\title{
Determinação do fator de erosividade da chuva para o distrito de Marudá (PA)
}

Em 1965 foi criado o modelo USLE (Universal Soil Loss Equation), que objetiva prever a erosão que ocorrerá em determinada área, servindo como método para auxiliar na tomada de decisão sobre o uso e o manejo do solo. O modelo relaciona seis fatores, entre eles o de erosividade da chuva (R), que tem sido o mais utilizado para análise da erosão hídrica, justamente por colaborar em projetos de dimensionamentos mais eficientes de obras hidráulicas. Assim, objetivou-se estimar o valor do Fator $\mathrm{R}$ para Marudá (PA) fazendo com que os dados sirvam como base para os municípios próximos, dado a escassez de informações mais atualizadas. Utilizou-se o período de 1994 a 2019, e se calculou o período de retorno e a probabilidade de ocorrência das chuvas erosivas. A erosividade média mensal das chuvas foi bastante variável, apresentando valores de 11,97 a 391,77 MJ mm ha-1 h-1 mês-1. A erosividade anual variou de $1.169,95$ (em 1998 ) a 2.481,17 MJ mm ha-1 h-1 ano-1 (em 2009). O valor do Fator R para Marudá é de 1.831,92 MJ mm ha-1 h-1 ano-1. O maior valor anual teve um período de retorno estimado em 27 anos com probabilidade de ocorrência de 3,7\%. Todas as informações obtidas no estudo podem ser utilizadas com segurança para localidades próximas e com características climáticas semelhantes, o que estende a possibilidade da utilização da Equação Universal de Perdas de Solo no planejamento tanto da atividade agrícola quanto urbana.

Palavras-chave: Potencial Erosivo; USLE; Planejamento.

\section{Determination of the rain erosivity factor for the district of Marudá (PA)}

In 1965, the USLE (Universal Soil Loss Equation) model was created, which aims to predict the erosion that will occur in a given area, serving as a method to assist in decision making on soil use and management. The model lists six factors, among them that of rain erosivity (R), which has been the most used for the analysis of water erosion, precisely because it collaborates in projects for more efficient sizing of hydraulic works. Thus, the objective was to estimate the value of the Factor R for Marudá (PA) making the data serve as a basis for the nearby municipalities, given the scarcity of more up-to-date information. The period from 1994 to 2019 was used, and the return period and the probability of erosive rains were also calculated. The monthly rainfall erosivity was quite variable, with values ranging from 11.97 a $391.77 \mathrm{MJ}$ mm ha-1 h-1 month-1. Annual erosivity ranged from 1,169.95 (in 1998) to 2,481.17 MJ mm ha-1 h-1 year-1 (in 2009 ). The value of the R Factor for Marudá is 1,831.92 MJ mm ha-1 h-1 year-1. The highest annual value had an estimated payback period of 27 years with a probability of $3.7 \%$. All information obtained in the study can be used safely for nearby locations and with similar climatic characteristics, which extends the possibility of using the Universal Soil Loss Equation in planning both agricultural and urban activities.

Keywords: Erosive potential; USLE; Planning.

Topic: Engenharia de Recursos Hídricos

Reviewed anonymously in the process of blind peer
Received: 05/09/2020

Approved: $\mathbf{1 0 / 1 1 / 2 0 2 0}$
Carlos Eduardo Aguiar de Souza Costa Universidade Federal do Pará, Brasil http://lattes.cnpq.br/2451471006212065 http://orcid.org/0000-0002-7238-6892 eduardoaguiarsc@hotmail.com

\section{Matheus Melo de Souza (iD)}

Universidade Federal do Pará, Brasil

http://lattes.cnpq.br/7609805744506221

http://orcid.org/0000-0002-8133-4963

matheus melo96@hotmail.com

\section{Carolina Costa Ramos (i)}

Universidade Federal do Pará, Brasil

http://lattes.cnpq.br/1300000847586457

http://orcid.org/0000-0001-6969-6593

carolinaramosufpa@gmail.com

\author{
Mayke Feitosa Progênio \\ Universidade Federal do Pará, Brasil \\ http://lattes.cnpq.br/5219122223495492 \\ http://orcid.org/0000-0002-1547-7018 \\ maykefeitosa@gmail.com \\ Karla Karoline Leite do Rosário (iD) \\ Universidade Federal do Pará, Brasil \\ http://lattes.cnpq.br/7554324212389148 \\ http://orcid.org/0000-0001-8919-9201 \\ karlaleite93@gmail.com \\ Gabrielle Souto da Rocha (iD) \\ Universidade Federal do Pará, Brasil \\ http://lattes.cnpq.br/9610153192666623 \\ http://orcid.org/0000-0001-5488-2246 \\ gabrielle.soutorocha@hotmail.com
}

\section{Referencing this:}

COSTA, C. E. A. S.; SOUZA, M. M.; RAMOS, C. C.; PROGÊNIO, M. F.; ROSARIO, K. K. L.; ROCHA, G. S.. Determinação do fator de erosividade da chuva para o distrito de Marudá (PA). Nature and Conservation, v.13, n.4, p.55-62, 2020. DOI: http://doi.org/10.6008/CBPC23182881.2020.004.0007

DOI: 10.6008/CBPC2318-2881.2020.004.0007 


\section{INTRODUÇÃO}

O potencial erosivo e sua intensidade estão ligados diretamente às condições físico-climáticas de cada região, como a precipitação, topografia e cobertura do solo. Segundo Corrêa et al. (2018), a erosão hídrica ocorre devido destacamento das partículas do solo pela ação da chuva, acarretando o transporte das partículas onde se depositam.

Um estudo desenvolvido pelo International Soil Reference and Information Centre e o United Nations Environment Programme informou que 15\% das terras no mundo já foram severamente degradados e $70 \%$ deste total correspondem às perdas da camada superficial do solo por erosão hídrica, sendo este processo uma das principais causas da redução da capacidade produtivas dos solos (ALMEIDA et al., 2011). Para contribuir com o planejamento de várias áreas, a utilização de modelos para previsão vem se intensificando.

A modelagem do processo erosivo é uma descrição matemática da desagregação, transporte e deposição das partículas na superfície do solo. Existem ao menos três motivos para realizar a modelagem da erosão: (a) os modelos podem ser utilizados como ferramentas de predição da erosão em planejamentos conservacionistas; (b) modelos fisicamente embasados podem prever onde e quando ocorrerá erosão, auxiliando no direcionamento de esforços para sua redução; e (c) estes modelos podem ser utilizados para entender o processo erosivo e suas interações a fim de direcionar pesquisas (NEARING et al., 1994).

Wischmeier e Smith em 1965 criaram o modelo USLE (Universal Soil Loss Equation), que tem por objetivo prever a erosão que ocorrerá em determinada área, servindo como método para auxiliar na tomada de decisão sobre o uso e o manejo do solo e, consequentemente, relacionar as práticas conservacionistas de maior eficiência (OTIM et al., 2019). Esta equação é considerada um bom instrumento na previsão das perdas de solo, exigindo um número de informações relativamente pequeno quando comparado aos modelos mais complexos sendo bastante conhecida e estudada no Brasil.

Segundo este modelo, a determinação do potencial erosivo consiste no produto dos fatores: erosividade (R), erodibilidade (K), topografia (LS), cobertura vegetal $(C)$ e práticas de conservação agrícolas (P). Lee et al. (2011) afirmam que o fator $\mathrm{R}$ tem sido o mais usado como o principal parâmetro na avaliação da erosão hídrica do solo, produção de sedimentos e monitoramento da qualidade da água. A motivação para o uso deste fator deve-se ao fato de que, dentre todas as outras variáveis, ele é o mais suscetível a mudanças climáticas e ambientais.

Para Falcão et al. (2018), as medidas preventivas sobre os danos causados por erosão hídrica consistem na adoção de um planejamento prévio em qualquer atividade ligada ao uso do solo. São escassos os trabalhos que abordam a erosividade das chuvas no nordeste paraense, diante disto, o objetivo deste estudo foi determinar fator de erosividade para Marudá, distrito do município de Marapanim (PA). As informações obtidas podem ser utilizadas para localidades próximas e com características climáticas semelhantes (ELTZ et al., 2013; CASSOL et al., 2008), principalmente no município de Curuçá, o que estende a possibilidade da utilização da Equação Universal de Perdas de Solo no planejamento tanto da atividade agrícola, quanto urbana, tendo em vista que essa região como um todo sofre com a erosão hídrica, sendo 
influenciando na economia rural ou em suas diversas estruturas do meio urbano.

\section{METODOLOGIA}

\section{Área de estudo}

Para a realização do estudo utilizou-se as precipitações do período de 1994 a 2019 registradas na estação pluviométrica 47005 do Serviço Geológico do Brasil (CPRM) localizada no distrito de Marudá (PA). A estação localiza-se as margens da principal via de acesso da área (PA-318), nas coordenadas 0 38' 01"W, 47 39' 30"S (Figura 1 e 2). O distrito possui 9.970 habitantes, o que equivale a $37,5 \%$ do total da população do Município (IBGE, 2010).

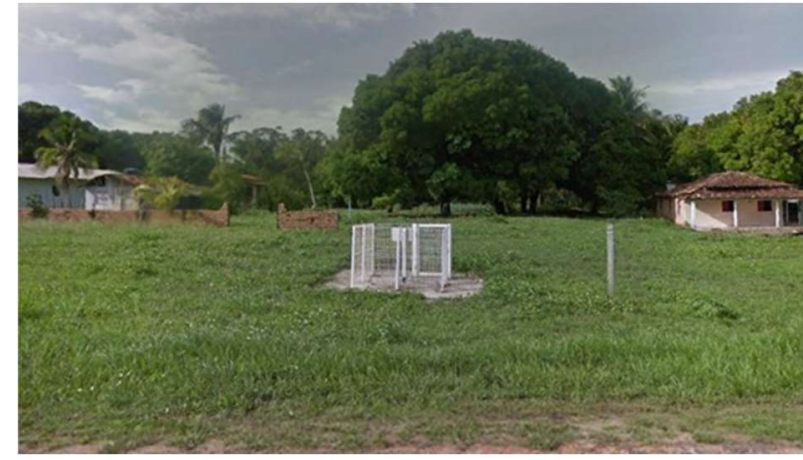

Figura 1: Localização da Estação Pluviométrica 47005.

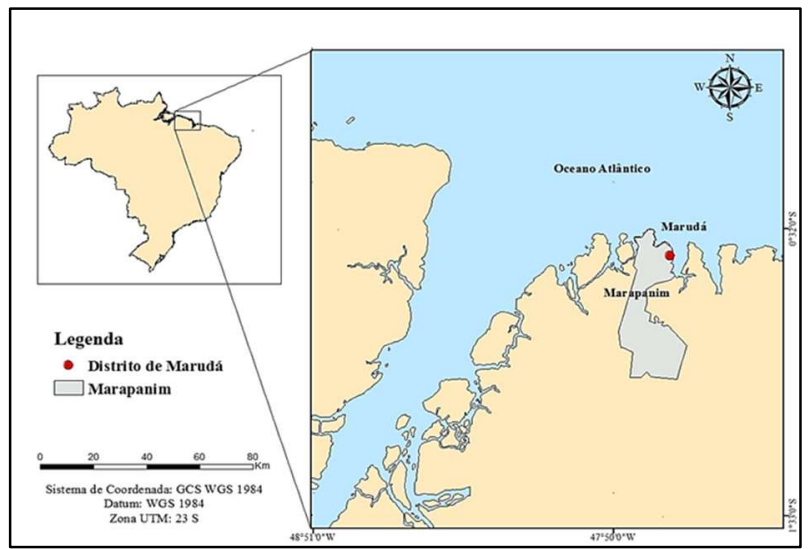

Figura 2: Mapa de localização do distrito de Marudá.

O estudo foi desenvolvido no distrito de Marudá localizado no litoral do Município de Marapanim (Zona do Salgado Paraense) instituído em 1914, pela Lei no 1.464, de 31 de agosto. Localiza-se na mesorregião do nordeste paraense, microrregião Salgado e dista cerca de $142 \mathrm{~km}$ da capital Belém (BRITO et al., 2019). Marudá dista 14 km da sede do município, com o qual se comunica Rodovia PA-318. A partir daí, segue a rodovia PA-136 até o município de Castanhal. Marudá é de existência posterior a 1930, estando o seu povoamento ligado à exploração pesqueira na costa norte do Pará e na contra-costa do Marajó (FERREIRA et al., 2005).

A pluviosidade média anual é de $2.600 \mathrm{~mm}$, com o período mais pesado a ocorrer entre dezembro e maio. A vegetação local é composta principalmente de restinga, mangues e muitas paisagens antropogênicas, incluindo florestas secundárias em vários estágios de sucessão (FERREIRA, 2009). Sua principal atividade econômica sempre foi a pesca, porém, a agricultura é uma atividade complementar muito forte na região.

\section{Índice de erosividade}

Foram determinados os índices de erosividade da chuva, seguidos dos seus períodos de retorno e probabilidade de ocorrência e sua correlação com o coeficiente de chuva local.

$\mathrm{O}$ índice de erosividade originalmente indicado foi o $\mathrm{El}_{30}$ que era determinado a partir do produto entre a energia cinética da chuva e a intensidade máxima ocorrida em 30 minutos, porém exigia grande quantidade de dados específicos, o que era um obstáculo (ROSA et al., 2018). A partir de então, outros 
trabalhos facilitaram o cálculo desta variável. A metodologia mais utilizada é a proposta por Silva (2004), que propôs que o Brasil fosse dividido em oito regiões homogêneas em termos de precipitação (Figura 3), sendo que cada região possuiria uma equação específica de acordo com as suas condições regionais. Marudá está na região 3 da divisão do trabalho citado, que possui como método de cálculo de erosividade a Equação 1 , criada por Oliveira et al. (1988).

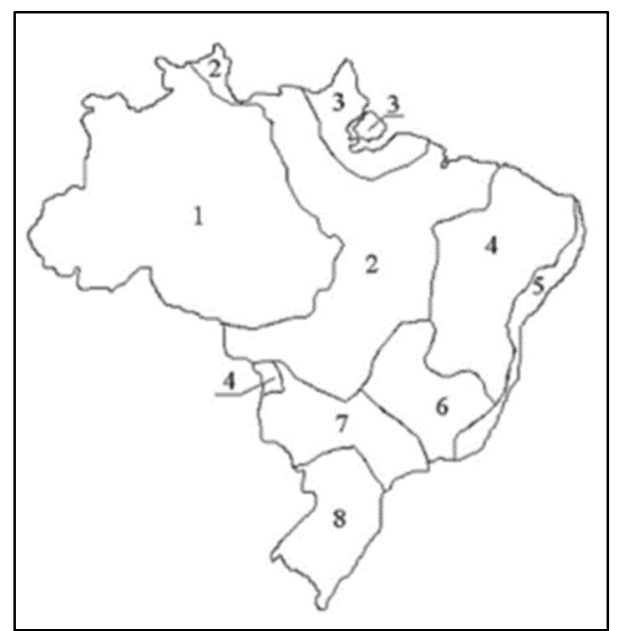

Figura 3: Mapa de determinação do fator energético da chuva. Fonte: Silva (2004).

$$
E i_{30}=0,66 . P_{m}+8,88
$$

Sendo o $\mathrm{Ei}_{30} \mathrm{o}$ índice de erosividade e Pm a precipitação média mensal.

A partir desta equação, foram calculados índices mensais erosividade para de 1998 a 2018 e a partir da soma dos índices mensais, foram gerados índices anuais para os 20 anos de dados, obtendo-se o Fator R. Vale ressaltar que este fator é a média dos índices de erosividade anuais.

De posse dos $\mathrm{El}_{30}$, foram calculadas as suas estatísticas descritivas, os períodos de retorno e suas probabilidades de ocorrência. Em seguida, para analisar a distribuição anual e mensal da porcentagem acumulada da erosividade, foram obtidos os valores relativos deste índice a partir da divisão da erosividade média mensal pelo seu valor médio anual, gerando valores relativos mensais referentes.

Por fim, calculou-se o coeficiente de chuva (Equação 2), de acordo como proposto por Lombardi Neto (1977), para cada mês correlacionando com os valores dos índices $\mathrm{El}_{30}$ para avaliar relação entre a ocorrência da precipitação e as de perdas de solo.

$$
R_{c}=\frac{p_{m}^{2}}{p_{a}}
$$

Sendo Rc o coeficiente de chuva, Pm a precipitação mensal e Pa a precipitação anual.

\section{RESULTADOS E DISCUSSÃO}

O fator de erosividade da chuva (R) para Marudá foi de 1.831,92 $\mathrm{MJ} \mathrm{mm} \mathrm{ha}^{-1} \mathrm{~h}^{-1} \mathrm{ano}^{-1}$. Os índices de erosividade da chuva apresentados para a região se mostraram muito baixos quando comparados aos apresentados para outras cidades, como o encontrado para Florianópolis-SC (BACK et al., 2017), Manaus-AM (FERNANDES, 2014). Este fato pode ter ocorrido devido à alta oscilação climática que a região sofre devido à Zona de Convergência Intertropical (ZCIT) e fenômenos climáticos interagindo. 
Tabela 1: Distribuição média mensal da precipitação, da erosividade absoluta e relativa e do coeficiente de chuva

\begin{tabular}{lllll}
\hline Mês & $\mathbf{P m}(\mathbf{m m})$ & Erosividade $\left(\mathbf{M J ~} \mathbf{~ m ~ h ~ h}^{-\mathbf{1}} \mathbf{h}^{-\mathbf{1}} \mathbf{~ m e ̂ s}^{-\mathbf{1}}\right)$ & Erosividade relativa (\%) & Rc (mm) \\
\hline Janeiro & 327,60 & 225,10 & 12,29 & 50,44 \\
Fevereiro & 425,29 & 289,57 & 15,81 & 78,62 \\
Março & 580,14 & 391,77 & 21,39 & 139,57 \\
Abril & 474,50 & 322,05 & 17,58 & 92,33 \\
Maio & 340,99 & 233,93 & 12,77 & 49,46 \\
Junho & 187,40 & 132,56 & 7,24 & 15,64 \\
Julho & 129,75 & 94,52 & 5,16 & 8,08 \\
Agosto & 30,55 & 29,04 & 1,59 & 0,59 \\
Setembro & 4,68 & 11,97 & 0,65 & 0,04 \\
Outubro & 10,87 & 16,05 & 0,88 & 0,37 \\
Novembro & 9,24 & 14,98 & 0,82 & 0,17 \\
Dezembro & 93,18 & 70,38 & 3,84 & 6,22 \\
\hline Anual & 2614,19 & $\mathbf{1 8 3 1 , 9 2}$ & 100 & - \\
\hline
\end{tabular}

A Amazônia possui três principais "polos" chuvosos, localizados: 1) no noroeste do estado do Amazonas, com volumes acima de 3.000 mm/ano; 2) na parte central da Amazônia, onde são registrados volumes superiores aos 2.500 mm/ano; e 3) entre o litoral do Amapá, a foz do rio Amazonas e parte do litoral no estado do Pará, com pluviosidade acima dos 4.000 mm/ano (MARENGO et al., 2009). Seguindo essa lógica, esperava-se também que a região de Marudá tivesse um maior número de chuvas erosivas, quando comparada a outros estudos, pincipalmente da região Sul do país.

A precipitação pluviométrica na Amazônia é largamente influenciada por características vigentes na região tropical do Oceano Atlântico, de onde provém importante parcela da umidade presente na região. A influência do Pacífico Equatorial, por sua vez, é mais complexa, pois o fenômeno El Niño Oscilação-Sul (ENOS) parece influenciar de maneira desigual os diferentes setores da região, além de apresentar expressões diversas conforme a época do ano em que ocorre. No contexto das teleconexões atmosféricas encontra-se uma possível explicação, já que são modificações nos padrões da pressão e da circulação atmosférica em uma dada região geográfica devido à influência de fatores remotos, de vários sistemas ou fenômenos (TRENBERTH et al., 1998).

Reboita et al. (2010) ressalta que é importante realizar estudos que tem como objetivo diagnosticar a influência conjunta do ENOS e das anomalias da TSM no Atlântico Tropical Norte e Sul no regime sazonal de precipitação pluviométrica das regiões Norte e Nordeste do Brasil, justamente para apurar esses comportamentos anômalos.

Com relação a estatística descritiva aplicada, a série de erosividade mensal variou de 11,97 a 391,77 MJ mm ha-1 $\mathrm{h}^{-1}$ mês $^{-1}$, apresentando desvio padrão de 5,85 a 129,45 MJ mm ha-1 $\mathrm{h}^{-1} \mathrm{mês}^{-1}$. O coeficiente de variação foi de $72,54 \%$ até $348,58 \%$. A Figura 4 demonstra a variação dessas estatísticas com relação aos meses.

Pode-se observar que os maiores valores de variabilidade foram para o período chuvoso, obviamente, representando também um maior risco de erosão hídrica durante o inverno amazônico. Porém, vale ressaltar que isso não exclui a possibilidade de chuvas erosivas acima do normal durante o período seco, pois mesmo com uma menor quantidade de dia chuvosos, pode ocorrer chuvas intensas (BARBOSA et al., 2005). 


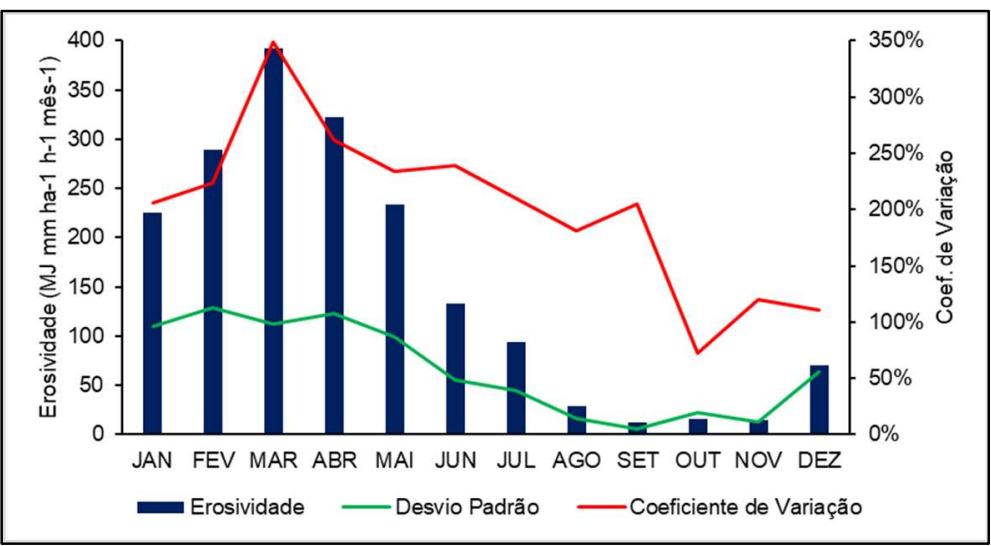

Figura 4: Erosividade média mensal e estatísticas descritivas

Os resultados do período de retorno e da probabilidade, determinados para o maior parâmetro de erosividade anual $(2.481,17)$ foram de 27 anos e 3,70\% (Tabela 2). Os períodos de retorno e probabilidade de ocorrência para o menor valor de erosividade $(1.169,95)$ foram, respectivamente, 1 ano e 96,3\%. O maior valor de erosividade foi para o ano de 2009, onde segundo Coutinho et al. (2019) ocorreram várias enchentes em território amazônico, podendo ser consequência de fortes chuvas nesse ano. Já a menor erosividade ocorreu para o ano de 1998, que segundo Antico et al. (2020) foi ano de ocorrência de um dos mais fortes eventos de El Niño no Oceano Pacífico, podendo estar correlacionado com as baixas de chuvas na Amazônia.

Tabela 2: Tempo de retorno (TR) e Probabilidade (P) dos valores anuais de erosividade

\begin{tabular}{|c|c|c|c|c|}
\hline Ano & Ordem & Erosividade (MJ mm ha-1 $\mathrm{h}^{-1} \mathrm{ano}^{-1}$ ) & TR (Anos) & $\mathbf{P}(\%)$ \\
\hline 2009 & 1 & $2.481,17$ & 27 & 3,70 \\
\hline 2014 & 2 & $2.449,63$ & 14 & 7,41 \\
\hline 1995 & 3 & $2.380,79$ & 9 & 11,11 \\
\hline 2019 & 4 & $2.291,05$ & 7 & 14,81 \\
\hline 2018 & 5 & $2.259,88$ & 5 & 18,52 \\
\hline 2011 & 6 & $2.211,30$ & 5 & 22,22 \\
\hline 1994 & 7 & $2.145,43$ & 4 & 25,93 \\
\hline 1996 & 8 & $2.016,20$ & 3 & 29,63 \\
\hline 2000 & 9 & $2.007,03$ & 3 & 33,33 \\
\hline 2008 & 10 & $1.964,46$ & 3 & 37,04 \\
\hline 2001 & 11 & $1.806,32$ & 2 & 40,74 \\
\hline 1999 & 12 & $1.798,54$ & 2 & 44,44 \\
\hline 2002 & 13 & $1.714,32$ & 2 & 48,15 \\
\hline 2004 & 14 & $1.695,25$ & 2 & 51,85 \\
\hline 2007 & 15 & $1.675,51$ & 2 & 55,56 \\
\hline 2015 & 16 & $1.668,78$ & 2 & 59,26 \\
\hline 2013 & 17 & $1.626,28$ & 2 & 62,96 \\
\hline 2003 & 18 & $1.614,07$ & 2 & 66,67 \\
\hline 1997 & 19 & $1.575,46$ & 1 & 70,37 \\
\hline 2006 & 20 & $1.563,31$ & 1 & 74,07 \\
\hline 2005 & 21 & $1.548,99$ & 1 & 77,78 \\
\hline 2012 & 22 & $1.537,97$ & 1 & 81,48 \\
\hline 2010 & 23 & $1.521,20$ & 1 & 85,19 \\
\hline 2017 & 24 & $1.449,40$ & 1 & 88,89 \\
\hline 2019 & 25 & $1.315,28$ & 1 & 92,59 \\
\hline 1998 & 26 & $1.169,95$ & 1 & 96,30 \\
\hline
\end{tabular}

A divergência climática da região fica ainda mais evidente quando se compara sua erosividade máxima e tempo de retorno com as de outros trabalhos. Por exemplo, Rosa et al. (2018) encontraram valores de 18.447 MJ mm ha-1 $\mathrm{h}^{-1}$ ano $^{-1}$, com um período de retorno de 28 anos e probabilidade de 3,6\% para Óbidos (PA). Já Rosa et al. (2016) encontraram em Rondon do Pará (PA) um valor máximo de $23.880 \mathrm{MJ}^{\mathrm{mm}} \mathrm{ha}^{-1} \mathrm{~h}$ 
${ }^{1}$ ano $^{-1}$, com período de retorno de 18 anos e probabilidades de 5,6\%. Estes valores sugerem uma grande variabilidade de erosividade da chuva para municípios diferentes dentro do estado, dada as suas proporções territoriais.

Mesmo com as diferenças com outros municípios paraenses, a hipótese de utilizar esses dados para regiões mais próximas (e com falta de estudos sobre erosividade da chuva) não pode ser descartada. A Figura 5 mostra a curva de regressão entre o índice de erosividade médio mensal e o coeficiente de chuva para a região. De acordo com a análise de regressão, observou-se grande correlação entre o fator erosividade médio mensal e o coeficiente de chuva local (Rc).

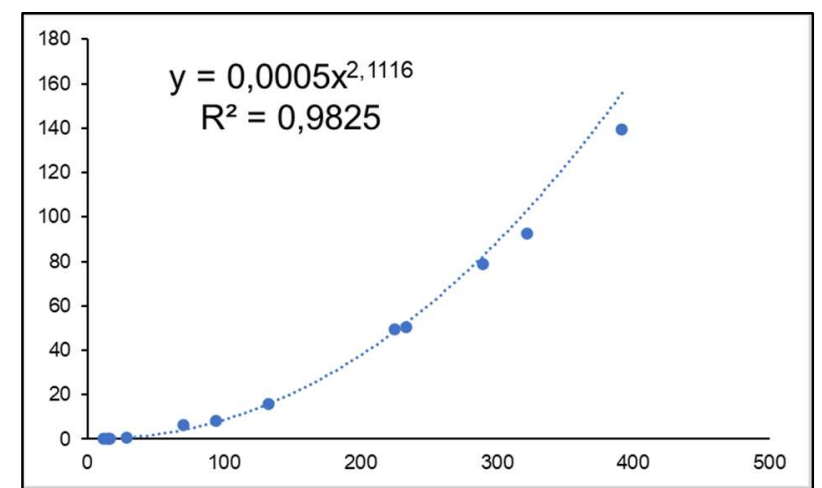

Figura 5: Regressão entre a erosividade média mensal e o coeficiente de chuva

Este resultado confirma o fato de que a erosividade mensal das chuvas no município pode ser medida utilizando dados de precipitação. O modelo matemático que apresentou a melhor correlação foi o potencial $\left(R^{2}=0,9825\right)$.

\section{CONCLUSÕES}

O fator erosividade da chuva para o município foi de $1.831,92 \mathrm{MJ} \mathrm{mm} \mathrm{ha}^{-1} \mathrm{~h}^{-1}$ ano-1. Entre os meses de janeiro a maio, verificou-se as maiores erosividades, indicando neste período uma provável maior perda anual de solo por erosão hídrica. Esse período coincidiu com o período de maior precipitação anual na região.

O maior parâmetro de erosividade anual teve um período de retorno de 27 anos e 3,70\% de probabilidade. O modelo matemático que apresentou a melhor correlação entre a erosividade média mensal e o coeficiente de chuva local foi o potencial, com alta correlação $\left(r^{2}=0,9825\right)$.

Essas informações são importantes ferramentas, sendo capazes de estabelecer em quais períodos do ano são prováveis maiores perdas de solo por processos erosivos. Os dados obtidos podem ser utilizados para localidades próximas e com características climáticas semelhantes, principalmente no Curuçá (PA).

\section{REFERÊNCIAS}

ALMEIDA, C. O. S.; AMORIM, R. S. S.; COUTO, E. G.; ELTZ, F. F.; BORGES, L. E.. Potencial erosivo da chuva de Cuiabá, MT: Distribuição e correlação com a precipitação pluviométrica. Revista Brasileira de Engenharia Agrícola e Ambiental, v.15, n.2, p.178-184, 2011. DOI: https://doi.org/10.1590/S1415$\underline{43662011000200011}$
ANTICO, A.; DIAZ, H. F.. Why was the Paraná flood of 2016 weaker than that of 1998 ?. International Journal of Climatology, v.40, n.1, p.604-609, 2020. DOI: https://doi.org/10.1002/joc.6204

BACK, Á. J.; POLETO, C.. Avaliação do Potencial Erosivo das Chuvas de Florianópolis/SC. Revista Brasileira de 
Climatologia, v.21, 2017. DOI:

http://dx.doi.org/10.5380/abclima.v21i0.49018

BARBOSA, T.; CORREIA, M.. Sistemas convectivos intensos no semiárido brasileiro: O controle da grande escala. Revista Brasileira de Meteorologia, v.20, n.3, p.395-410, 2005.

BRITO, F. S. L.; PIMENTEL, B. A.; MORAIS, M. S.; ROSÁRIO, K. K. L.; CRUZ, R. H. R.. Impactos socioambientais provocados por um vazadouro a céu aberto: uma análise no distrito de Marudá/PA. Revista Ibero-Americana de Ciências Ambientais, v.10, n.5, p.128-139, 2019. DOI: https://doi.org/10.6008/CBPC2179-6858.2019.005.0012

CASSOL, E. A.; ELTZ, F. L.; MARTINS, D.; LEMOS, A. M.; LIMA, V. S.; BUENO, A. C.. Erosividade, padrões hidrológicos, período de retorno e probabilidade de ocorrência das chuvas em São Borja, RS. Revista Brasileira de Ciência do Solo, v.32, n.3, p.1239-1251, 2008. DOI: https://doi.org/10.1590/S0100-06832008000300032

CORRÊA, E.; MORAES, I. C.; CUNHA, C. M. L.; PINTO, S. A. F.. Influência do Cultivo de Cana-de-Açúcar nas Perdas de Solo por Erosão Hídrica em Cambissolos no Estado de São Paulo. Revista Brasileira de Geomorfologia, v.19, n.2, 2018. DOI: http://dx.doi.org/10.20502/rbg.v19i2.1303

COUTINHO, E. C.; ROCHA, E. J. P.; LIMA, A. M. M.; RIBEIRO, H. M. C.. Variabilidade do regime hidrológico da bacia Amazônica. Boletim de Geografia, v.37, n.2, 2019. DOI: https://doi.org/10.4025/bolgeogr.v37i2.38424

ELTZ, F. L. F.; CASSOL, E. A.; PASCOTINI, P. B.; AMORIM, R. S. S.. Erosive potential and rainfall characteristics of São Gabriel, RS, Brazil, from 1963 to 1993. Revista Brasileira de Engenharia Agrícola e Ambiental, v.17, n.6, p.647-654, 2013. DOI: http://dx.doi.org/10.1590/S141543662013000600011

FALCÃO, K. S.; LEITE, E. F.. Avaliação do Potencial Natural à Erosão Hídrica na Bacia do Rio Nioaque. Revista Geoaraguaia, v.8, n.3, 2018.

FERNANDES, M.. Índice de erosividade da chuva média anual para Manaus/AM de 1981 a 2010. Revista Geonorte, v.5, n.18, p.46-49, 2014.

FERREIRA, M. C.. Medicinal knowledge and plant utilization in an Amazonian coastal community of Marudá, Pará State (Brazil). Journal of Ethnopharmacology, v.126, n.1, p.159175, 2009. DOI: https://doi.org/10.1016/j.jep.2009.07.016

FERREIRA, M. C.; SILVA, M. F. F.. A fitofarmacopéia da comunidade pesqueira de Marudá, litoral paraense. Boletim do Museu Paraense Emílio Goeldi, v.1, p.33-45, 2005.
IBGE. Instituto Brasileiro de Geografia e Estatística. Diretoria de Pesquisas. Coordenação de População e Indicadores Sociais. Cidades, Marapanim/PA. Rio Janeiro: IBGE, 2010.

LEE, J.-H.; HEO, J.-H.. Evaluation of estimation methods for rainfall erosivity based on annual precipitation in Korea. Journal of Hydrology, v.409, n.1-2, p.30-48, 2011. DOI: https://doi.org/10.1016/j.jhydrol.2011.07.031

LOMBARDI NETO, F.. Rainfall erosivity-its distribution and relationship with soil loss at Campinas, Brazil. Dissertation (Masters) - Purdue University, West Lafayette, 1977.

MARENGO, J.; NOBRE, C.. Clima da região amazônica. In: CAVALCANTI, I. F. A.. Tempo e Clima do Brasil. São Paulo: Oficina de Textos, 2009. p.198-212.

NEARING, M. A.; LANE, L. J.; LOPES V. L.. Modeling soil erosion. In: LAL, R.. Erosion Research Methods, Soil and Water Conservation Society and St. Lucie Press. 1994. p.127-156.

OLIVEIRA JUNIOR, R. C.. A erosividade das chuvas na parte leste do Pará. Dissertação (Mestrado) - Faculdade de Ciências Agrárias do Pará, Belém, 1988.

OTIM, D.; SMITHERS, J.; SENZANJE, A.; VAN ANTWERPEN, R.. Design norms for soil and water conservation structures in the sugar industry of South Africa. Water SA, v.45, n.1, p.2940, 2019. DOI: https://doi.org/10.4314/wsa.v45i1.04

REBOITA, M. S.; GAN, M. A.; ROCHA, R. P.; AMBRIZZI, T.. Regimes de precipitação na América do Sul: uma revisão bibliográfica. Revista brasileira de Meteorologia, v.25, n.2, p.185-204, 2010. DOI: https://doi.org/10.1590/S010277862010000200004

ROSA, A. G.; SOUSA, A.; M. L.; COSTA, J. A.; SOUZA, E. B. Erosividade da chuva em Rondon do Pará, PA, Brasil de 1999 a 2015 e projetada para 2035. Revista Ambiente \& Água, v.11, n.4, p.1006-1021, 2016. DOI: https://doi.org/10.4136/ambi-agua.1956

ROSA, A. G.; SOUSA, A. M. L.. Erosividade da Chuva: Distribuição e Correlação com a Precipitação em Óbidos/PA (Brasil). Revista GeoAmazônia, v.6, n.11, p.256-272, 2018.

SILVA, A. M.. Rainfall erosivity map for Brazil. Catena, v.57, n.3, p.251-259, 2004. DOI: https://doi.org/10.1016/j.catena.2003.11.006

TRENBERTH, K. E.; BRANSTATOR, G. W.; KAROLY, D.; KUMAR, A.; LAU, N.-C.; ROPELEWSKI, C.. Progress during TOGA in understanding and modeling global teleconnections associated with tropical sea surface temperatures. Journal of Geophysical Research: Oceans, v.103, n.C7, p.1429114324, 1998. DOI: https://doi.org/10.1029/97JC01444

A CBPC - Companhia Brasileira de Produção Científica (CNPJ: 11.221.422/0001-03) detém os direitos materiais desta publicação. Os direitos referem-se à publicação do trabalho em qualquer parte do mundo, incluindo os direitos às renovações, expansões e disseminações da contribuição, bem como outros direitos subsidiários. Todos os trabalhos publicados eletronicamente poderão posteriormente ser publicados em coletâneas impressas sob coordenação da Sustenere Publishing, da Companhia Brasileira de Produção Científica e seus parceiros autorizados. Os (as) autores (as) preservam os direitos autorais, mas não têm permissão para a publicação da contribuição em outro meio, impresso ou digital, em português ou em tradução. 